Received: $\quad 2015.12 .27$

Accepted: 2016.01.18

Published: 2016.02.24

\title{
Authors' Contribution:
}

Study Design A

Data Collection B

Statistical Analysis C

Data Interpretation D

Manuscript Preparation E

Literature Search F

Funds Collection G

Corresponding Author: Source of support:

Background:

Material/methods:

\section{MiR-494 Inhibits Epithelial Ovarian Cancer Growth by Targeting c-Myc}

Department of Gynecology and Obstetrics, West China Second University Hospital, Sichuan University, Chengdu, Sichuan, P.R. China

Mingrong Xi, e-mail: qmrjzz@126.com

Departmental sources

Results: MiR-494 showed low levels in EOC tissues and cells. Overexpression of miR-494 inhibited cell growth and migration of EOC cells and vice versa. c-Myc is the targeted gene of miR-494.

Conclusions: MiR-494 has an anti-tumor role in EOC via c-Myc.

MeSH Keywords: Cell Growth Processes $\bullet$ Genes, myc $\bullet$ MicroRNAs • Ovarian Neoplasms

Full-text PDF: $\quad$ http://www.medscimonit.com/abstract/index/idArt/897288

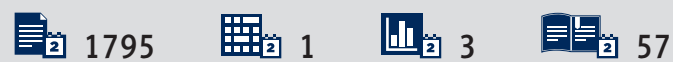




\section{Background}

Ovarian cancer is the most lethal malignant gynecological cancer [1], and is a heterogeneous disease associated with family history of cancer, genetic risk, and the histopathology [2]. EOC is the most common type, accounting for $95 \%$ of invasive ovarian cancer cases. The standard treatment is aggressive surgery followed by platinum-taxane chemotherapy [3-7]. Although surgery and platinum-based chemotherapy currently are the cornerstone of standard ovarian cancer management pathways, new therapy strategies are urgently required to improve outcomes. Thus, understanding of the molecular pathogenesis of ovarian cancer is required.

MiRNAs are evolutionarily conserved small non-coding RNAs involved in the regulation of gene expression and protein translation [8]. miRNAs play roles in the pathogenesis of various cancers [9-14]. Similarly, many miRNAs in EOC are found at abnormal levels [15-21].

miR-494 has been studied in various tumors. In non-small cell lung cancer, miR-494 can induce tumor necrosis factor-related apoptosis-inducing ligand (TRAIL) resistance and regulates the G1/S transition during liver tumorigenesis [22,23]. On the contrary, miR-494 showed low levels in gastric cancer, breast cancer, prostate cancer, and cholangiocarcinomas, and overexpression of miR-494 inhibited the cancer growth [24]. In gastric carcinoma, miR-494 acts as an anti-oncogene by targeting c-Myc [25]. However, the role of miR-494 in EOC remains unknown.

In the present study, we investigated the function of miR-494 and c-Myc in ovarian cancer, and found that miR-494 acts as an anti-oncogene by targeting c-Myc in e EOC. We hope our data may provide a better understanding of the pathogenesis of EOC.

\section{Material and Methods}

\section{Patients}

Fifteen EOC specimens were collected from the Department of Gynecology and Obstetrics, West China Second University Hospital, Sichuan University. Tissue samples were immediately frozen in liquid nitrogen after isolation. Informed consent was obtained from each patient. The Ethics Commitment of Sichuan Provincial Cancer Hospital and the Ethics Committee of Sichuan University approved this study. The senior pathologists of Sichuan Provincial Cancer Hospital evaluated the histological features of the specimens. The clinical information of the 15 EOC patients are provide in Supplementary Table 1.

\section{Cell culture}

EOC cell lines SKOV3, HO8910, and HEK293 were purchased from the American Type Culture Collection (ATCC, Rockville, MD, USA). SKOV3, HO8910, and HEK293 cells were maintained in DMEM with $10 \%$ fetal bovine serum (FBS) (Invitrogen Corp, Grand Island, NY, USA) [26].

\section{Detection of miR-494 and c-Myc level in ovarian cancer tissues or cells}

Total RNAs of EOC tissues and cells were extracted by TRIzol reagent (Invitrogen Corp, Grand Island, NY, USA) according the manufacturer's instructions. The total RNAs was reverse-transcribed to cDNA by using the All-in-one ${ }^{\mathrm{TM}}$ miRNA First-Strand cDNA Synthesis Kit (Invitrogen Corp, Grand Island, NY, USA). The primers were designed and synthesized by Shengong Company (Shengong, Shanghai, China). Real-time PCR assay was performed as described previously [12,27-29].

\section{Oligonucleotides and cell transfection}

miR-494 antisense oligonucleotides (miR-494 ASO), miR-494 mimics, and negative control miRNA were purchased from RiboBio (Guangdong, China). MiR-494 ASO or MiR-494 mimics were transfected into cells by using Lipofectamine (Invitrogen, Shanghai, China), according to the manufacturer' s instructions [27].

\section{Cell proliferation and migration assay}

After $24 \mathrm{~h}$ of transfection of miR-494 mimics and miR-494 ASO, SKOV 3 and HO8910 cells $\left(5 \times 10^{3} /\right.$ well) were seeded into 96-well plates. Then MTT experiments were performed as previously described [30-32]. Absorbance in each well was measured by using a microplate reader set at $570 \mathrm{~nm}$. To measure cell migration, 8-mm pore size culture inserts (Transwell; Falcon, BD Biosciences) were placed into wells of 24-well culture plates, separating the upper and lower chambers. In the lower chamber, $600 \mu \mathrm{L}$ DMEM containing 10\% FBS was added. Then $1 \times 10^{5} /$ well cells were added to the upper chamber. After $24 \mathrm{~h}$ incubation, migrated cells were counted by use of a counting chamber (Shengong, Shanghai, China) [33].

\section{MYC amplification and expression in different types of cancer analysis}

MYC amplification data and graph were obtained from cBioPortal for Cancer Genomics [34,35]. The MYC expression in tumor data was from Gene Expression Omnibus (GEO) (http:// www.ncbi.nlm.nih.gov/geo/). 
Supplementary Table 1. Clinical information.

\begin{tabular}{|c|c|c|c|c|}
\hline No & Age (years) & Type & Stage & Differentiation \\
\hline 1 & 57 & Epithelial ovarian cancer/serous & III & Low \\
\hline 2 & 59 & Epithelial ovarian cancer/serous & IV & Moderate \\
\hline 3 & 57 & Epithelial ovarian cancer/serous & III & Moderate \\
\hline 4 & 36 & Epithelial ovarian cancer/serous & IV & Moderate \\
\hline 5 & 68 & Epithelial ovarian cancer/serous & IV & Moderate \\
\hline 6 & 49 & Epithelial ovarian cancer/serous & IV & Low \\
\hline 7 & 55 & Epithelial ovarian cancer/serous & III & Moderate \\
\hline 8 & 66 & Epithelial ovarian cancer/serous & IV & Low \\
\hline 9 & 65 & Epithelial ovarian cancer/serous & III & Moderate \\
\hline 10 & 45 & Epithelial ovarian cancer/serous & IV & Low \\
\hline 11 & 56 & Epithelial ovarian cancer/serous & III & Low \\
\hline 12 & 59 & Epithelial ovarian cancer/serous & III & Moderate \\
\hline 13 & 61 & Epithelial ovarian cancer/serous & IV & Low \\
\hline 14 & 65 & Epithelial ovarian cancer/serous & IV & Moderate \\
\hline 15 & 66 & Epithelial ovarian cancer/serous & III & Moderate \\
\hline
\end{tabular}

\section{Target prediction}

Bioinformatics methods were applied for the prediction of the targeted genes of miR-494. In detail, the bioinformatics algorithms from TargetScanHuman were used [36-41].

\section{Dual luciferase assays}

To confirm whether c-Myc directly bind to miR-494, a dual luciferase assay was performed [42,43]. The 3'UTR of c-Myc was amplified by using PCR from genomic DNA. The production was inserted into the downstream of c-Myc 3'UTR reporter plasmids (pRL-c-Myc) (Biotech, Chengdu, China), and mutants of c-Myc 3'UTR were generated by use of a Site-Directed Mutagenesis kit (Shanghai, China). Then the whole plasmid was confirmed by sequencing. Mutation in the miR-494 binding site of the c-Myc 3'UTR were constructed by Shengong Company (Shengong, Chengdu, China). The luciferase reporter-containing mutant was constructed. For luciferase assays, HEK293 were transfected with luciferase reporter plasmid along with miR494 mimics or negative control by using Lipofectamine 2000 (Invitrogen, Shanghai, China). At $24 \mathrm{~h}$ after transfection, these cells were analyzed by using a luciferase assay kit (Promega, Madison, WI, USA) [44].

\section{Western blot}

At $48 \mathrm{~h}$ after treatment, cells were washed with cold PBS and subjected to a lysis buffer. Protein lysates were separated using $8 \%$ SDS-polyacrylamide gel electrophoresis, then electrotransferred onto nitrocellulose filter membranes. The membranes were blocked with a buffer containing $5 \%$ non-fat milk in PBS with $0.05 \%$ Tween-20 for $2 \mathrm{~h}$ and incubated with primary antibody (anti-c-Myc) overnight. Then membranes were incubated with peroxidase-conjugated secondary antibodies (Milli-pore, Darmstadt, Germany) and developed with an enhanced chemiluminescence detection kit (Pierce, Rockford, IL). $\beta$-actin was used as blank control.

\section{Statistical analysis}

The data are the mean \pm S.D. from 3 independent experiments. When only 2 groups were compared, the difference between them was analyzed using a 2-tailed Student's t test. However, when 3 or more groups were compared, the difference among them was analyzed using ANOVA. Statistically significant differences in the expression of miR-494 between matched pairs were detected by the Wilcoxon matched-pairs signed rank test. SPSS software (version 17.0) was used to perform statistical analyses, in which $\mathrm{P}<0.05$ was significant. 


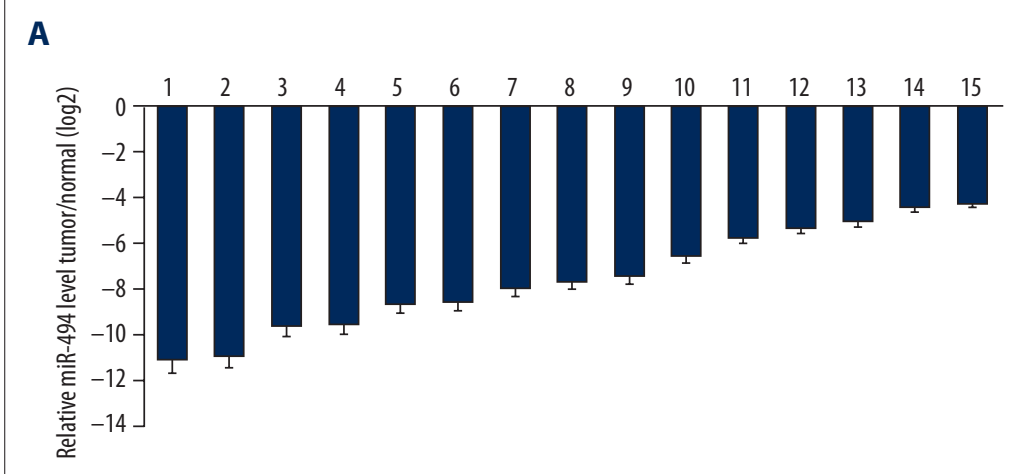

B

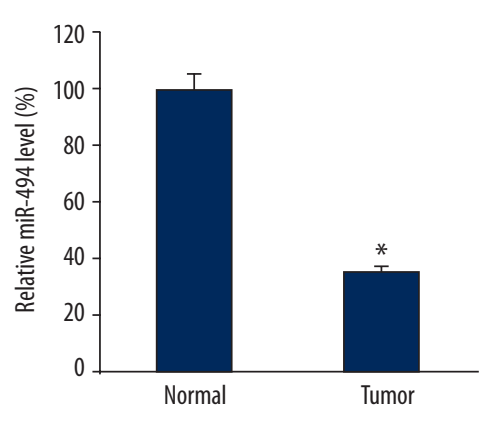

Figure 1. The miR-494 level in epithelial ovarian cancer tissues. The miR-494 levels in the 15 EOC tissues and matched adjacent normal cancer tissues were tested by qRT-PCR. U6 snRNA was used as blank control (A). The mean expression of miR494 in the 15 EOC tissues and matched adjacent normal cancer tissues were calculated, and the mean level of 15 normal ovarian tissues were arbitrarily defined as $100 \%$ (B). The qRT-PCR experiments were performed 3 times. Data are mean \pm S.D. * $P<0.05$

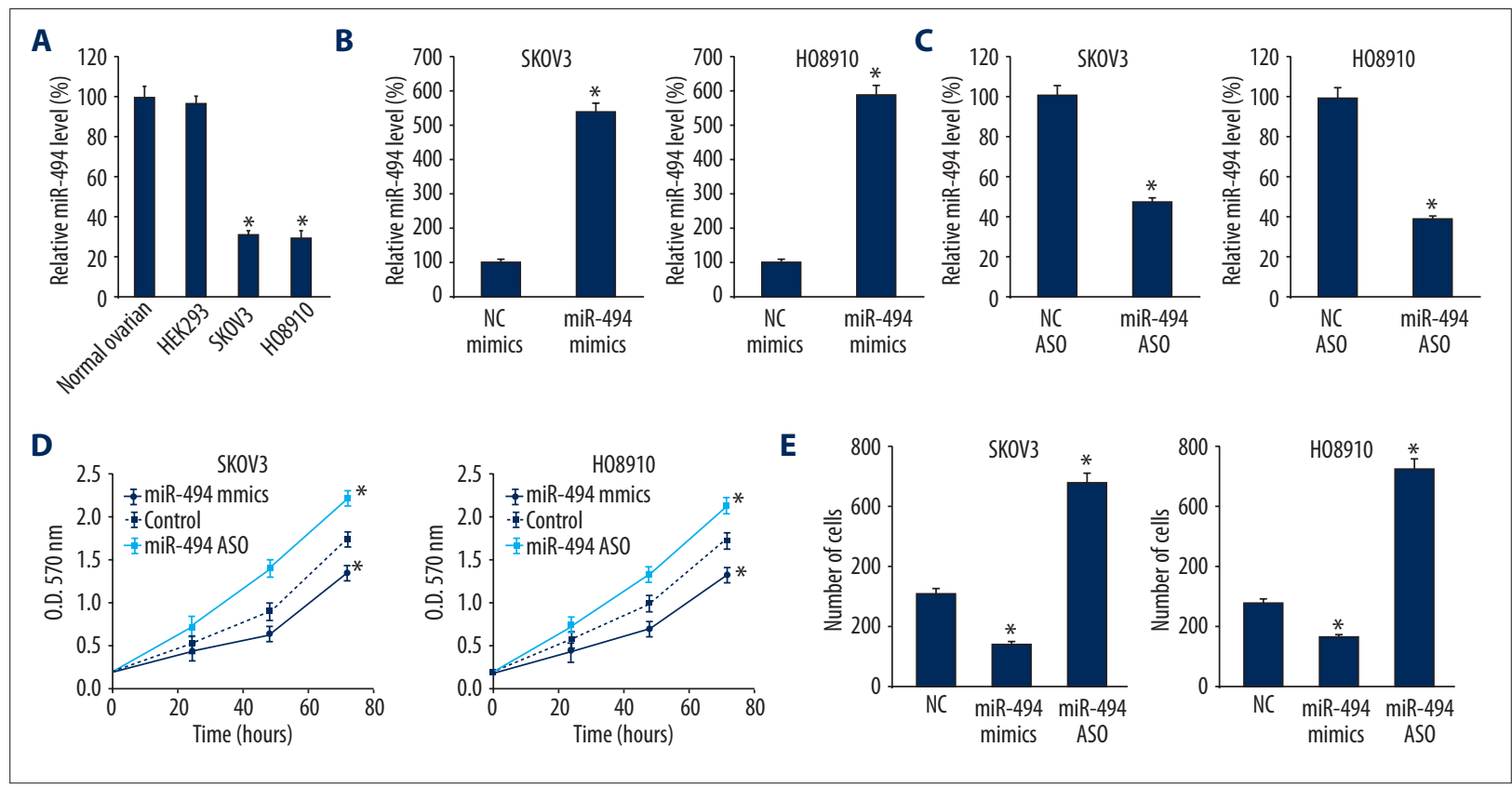

Figure 2. Overexpression of miR-494 inhibited cells growth and invasion and vice versa. The miR-494 levels in normal ovarian tissues, HEK293, SKOV3, and HO8910 cells were tested by qRT-PCR. The miR-494 level in normal ovarian tissues was deliberately treated as 100\% (A). After miR-494 mimics transfection, the miR-494 levels in SKOV3 and H08910 cells were examined. The miR-494 level in negative control was deliberately treated as 100\% (B). After miR-494 ASO transfection, the miR-494 levels in SKOV3 and HO8910 cells were examined. The miR-494 level in negative control transfected cells was deliberately treated as $100 \%$ (C). After miR-494 mimics or miR-494 ASO transfection, the cellular proliferation of SKOV3 and HO8910 were tested by MTT analysis (D). After miR-494 mimics or miR-494 ASO transfection, cells were collected for migration test (E). The experiments were performed 3 times. Data are mean \pm S.D. ${ }^{*} P<0.05$

Figure 3. c-Myc was targeted by miR-494. Alterations of c-Myc were visualized by cBioPortal for Cancer Genomics. Mutation, deletion, amplification, and other alterations are shown in different colors. The most frequent alteration of c-Myc in different types of cancer is amplification. The CAN data stand for copy number alteration data (A). The binding site for miR-494 in c-Myc was mutated (B). HEK293 cells were co-transfected with miR-494 mimics or control and reporter plasmid or the mutant 3'UTR of c-Myc, together with the controls. At $48 \mathrm{~h}$ after transfection, the luciferase activity was measured (C). MiR-494 mimics was transfected into HEK293 cells. At $48 \mathrm{~h}$ later, the c-Myc protein level was tested by Western blot (D). The mRNA levels of c-Myc in 15 EOC tissues were assayed by qRT-PCR (E). The experiments were performed 3 times. Data are mean \pm S.D. ${ }^{*} P<0.05$ 


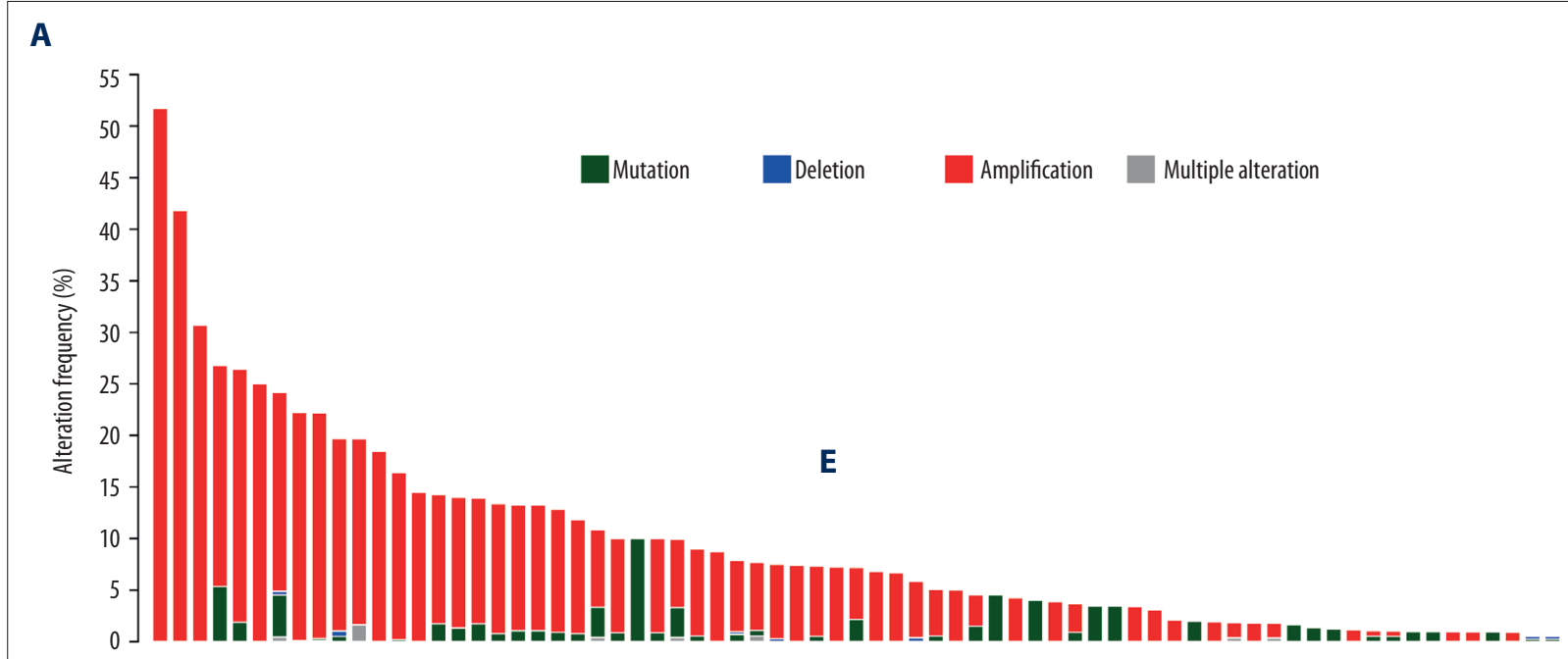

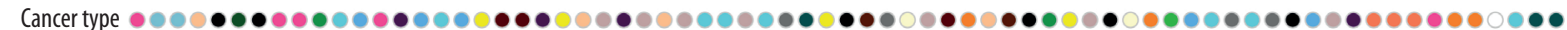
Mutation data +++++++++++-+++++++++++++++++++++++++++++++++++++++++++++++++++++++++

CNA data + + + + + + + + + + + + + + + + + + + + + + + + + + + + + + + + + + + + + + + + + + - + - + + - + + + + + + + + + - . + + + - + + + + + +

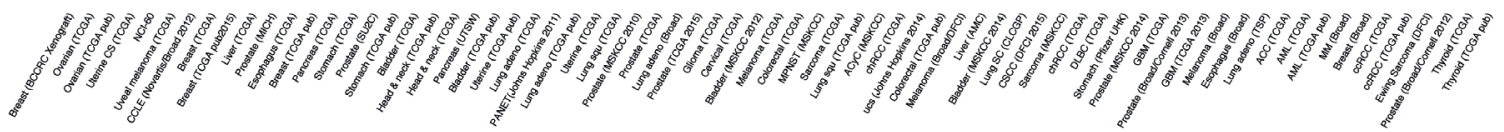

B

$\begin{array}{rrr}\text { Position 61-67 of MYC 3' UTR } & 5^{\prime} \quad \text {...AAUCACCUAUGAACUUGUUUCAA... } \\ \text { hsa-miR-494 } & 3^{\prime} \quad \begin{array}{l}\text { CUCCAAAGGGCACAUACAAAGU } \\ *\end{array}\end{array}$

Position 61-67 of MYC 3' UTR $\quad 5 ' \quad$...AAUCACCUAUGAACUAAAAAAAA...

C

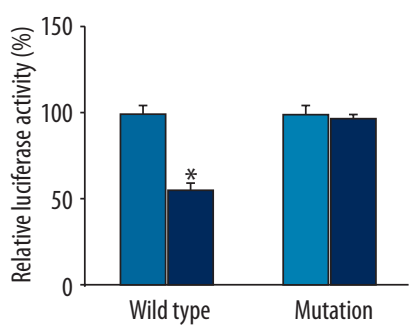

$\mathbf{F}$
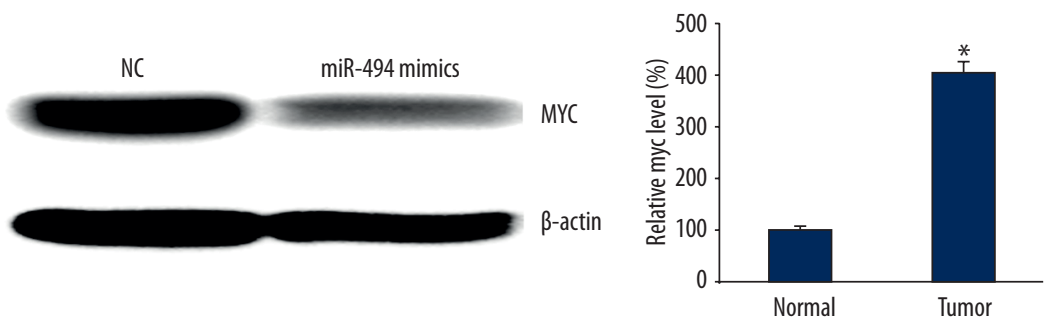

E

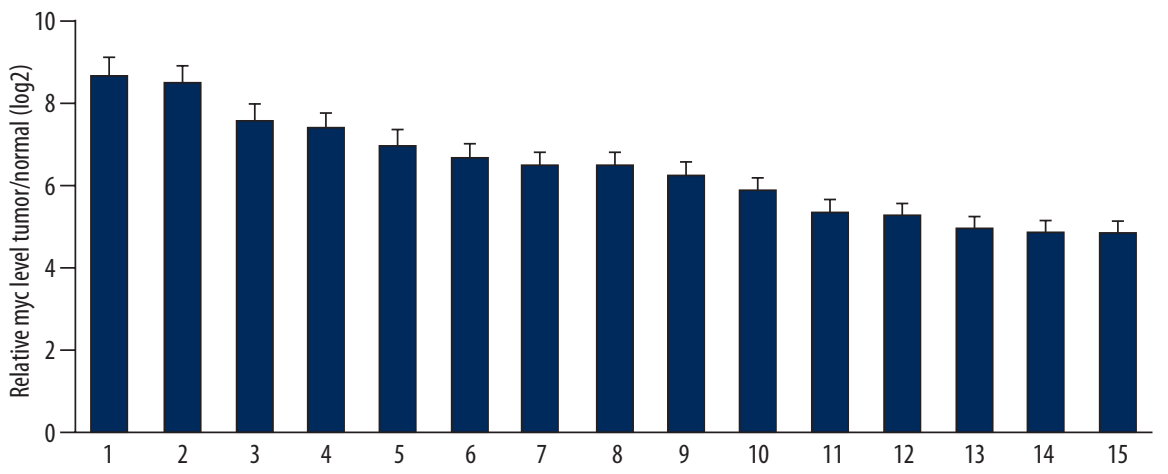




\section{Results}

\section{The lower expression of miR-494 in EOC tissues}

We collected 15 EOC tissues from our hospital, then the miR494 levels in each cancer tissue and matched adjacent normal tissue were assayed by qRT-PCR, and we found that all EOC tissues showed lower levels of miR-494 (Figure 1A). Then we calculated the mean level of miR-494 in the 15 cancer tissues and normal tissues, and found that the mean expression of miR-494 in the 15 cancer tissues was lower than the mean expression in normal tissues (Figure 1B).

\section{The in vitro function of miR-494}

Next we tested the function of miR-494 in vitro. EOC cell lines SKOV3 and H08910 were tested by qRT-PCR for the miR-494 levels and the miR-494 levels in normal ovarian tissues, and HEK293 was used as negative control. Unsurprisingly, miR-494 levels in SKOV3 and H08910 cells were lower than in miR494 levels in normal ovarian and HEK293 cells (Figure 2A). Next, we overexpressed or suppressed miR-494 levels in SKOV3 and HO8910 by transfection of miR-494 mimics or miR-494 ASO. At $48 \mathrm{~h}$ following the transfection, the miR494 levels in the 2 cell lines were tested, and we found that transfection of miR-494 mimics overexpressed the miR-494 levels and transfection of miR-494 ASO suppressed the miR494 levels (Figure 2B, 2C). Next, proliferation of SKOV3 and H08910 cells were assayed by MTT analysis. We found that overexpression of miR-494 inhibited cell proliferation and suppression of miR-494 promoted cell proliferation (Figure 2D). Migration assay showed that miR-494 mimics inhibited the migration of SKOV3 and HO8910 cells and miR-494 ASO promoted cell migration (Figure $2 \mathrm{E}$ ).

\section{c-Myc was targeted by miR-494}

A previous study showed that c-Myc was targeted by miR-494 in gastric cancer [25], and we wondered whether miR-494 targeted c-Myc in ovarian cancer. To reveal the role of c-Myc, we queried The Cancer Genome Atlas (TCGA). The TCGA Project is a large-scale collaborative effort to characterize the genomic changes that occur in cancer. This project has profiled and analyzed large numbers of human tumors to discover and catalog molecular aberrations at the DNA, RNA, protein, and epigenetic levels [45]. We found c-Myc showed amplification in most types of cancer (Figure 3A). Next, we identified the binding sites between miR-494 and c-Myc, and the mutated version of c-Myc was also displayed (Figure 3B). The effect of miR-494 on the c-Myc translation was tested by luciferase reporter assay using luciferase reporter plasmid constructed with wildtype 3'UTR of c-Myc or mutant. We found that overexpression of miR-494 significantly reduced the luciferase activity of the reporter gene with wild-type 3'UTR of c-Myc, but not with the mutant (Figure 3C). Next, we tested the c-MYC protein level in HEK293 cells, and found the c-MYC protein level was suppressed following miR-494 transfection (Figure 3D). We then assayed the c-Myc mRNA levels in the 15 epithelial ovarian cancers, and found that in all cancer tissues, c-Myc showed higher levels (Figure 3E), and the mean expression of c-Myc in the 15 cancer tissues was higher than the mean expression in normal tissues (Figure 3F).

\section{Discussion}

In this study we tested the function of miR-494 in EOC. We found that miR-494 showed a lower level in cancer tissues, and overexpression of miR-494 suppressed the cellular proliferation and immigration. We also found that $c-M y c$ can be targeted by miR-494 in EOC cells.

The $c-M y c$ gene has been study for a long time. In 1983, Minna et al. found amplification and expression of the c-Myc oncogene in human lung cancer cell lines [46]. The oncogene role of $c-M y c$ has been well studied. The $c-M y c$ oncogene is activated in many types of cancer [47]. The c-Myc transcription factor regulates numerous processes, including epithelialmesenchymal transition, metastasis, stemness, angiogenesis, and cell cycle progression [48]. Here, we found that miR-494 targeted $c-M y c$ and miR-494 inhibited cellular proliferation; therefore, we hypothesized that miR-494 plays a role in ovarian cancer via c-Myc.

Interestingly, c-Myc can induce many miRNAs, including miR-9, miR-17, miR-18a, miR-19a, miR-20a, miR-22, and miR-25. These genes take part in many complicated processes, such as epithelial-mesenchymal transition, metastasis, angiogenesis, apoptosis, and heart development and reprogramming [48], suggesting that $c-M y c$ stayed in the center of the molecular network.

The function of miR-494 has been revealed in various cancers. miR-494 is a tumor-suppressive miRNA in prostate cancer, pancreatic cancer, cholangiocarcinoma, ovarian cancer, and lung cancer [49-54], and showed oncogenic roles in hepatocellular carcinoma, retinoblastoma, and bronchial carcinogenesis [55-57]. The most common explanation is that miR494 targets different genes in various cancers. However, why miR-494 targets certain genes in certain types of cancer needs further exploration.

\section{Conclusions}

Our study shows the role miR-494 in EOC. We found that miR494 is a tumor suppressor in EOC by targeting c-Myc. We hoped 
that our data provide useful insights into a new mechanism of miR-494 in EOC.

\section{References:}

1. Torre LA, Bray F, Siegel RL et al: Global cancer statistics, 2012. Cancer J Clin, 2015; 65: 87-108

2. Schildkraut JM, Iversen ES, Akushevich L et al: Molecular signatures of epithelial ovarian cancer: analysis of associations with tumor characteristics and epidemiologic risk factors. Cancer Epidemiol Biomarkers Prev, 2013; 22(10): 1709-21

3. Rooth C: Ovarian cancer: risk factors, treatment and management. $\mathrm{Br} J$ Nurs, 2013; 22: S23-30

4. Bristow RE, Tomacruz RS, Armstrong DK et al: Survival effect of maximal cytoreductive surgery for advanced ovarian carcinoma during the platinum era: A meta-analysis. J Clin Oncol, 2002; 20: 1248-59

5. Winter-Roach BA, Kitchener HC, Lawrie TA: Adjuvant (post-surgery) chemotherapy for early stage epithelial ovarian cancer. Cochrane Database Syst Rev, 2012; 2012: CD004706

6. Winter-Roach BA, Kitchener HC, Dickinson HO: Adjuvant (post-surgery) chemotherapy for early stage epithelial ovarian cancer, Cochrane Database Syst Rev, 2009; 2009: CD004706.

7. Cancer Genome Atlas Research Network: Integrated genomic analyses of ovarian carcinoma. Nature, 2011; 474: 609-15 [Nature, 2012; 490: 298]

8. Giordano S, Columbano A: MicroRNAs: New tools for diagnosis, prognosis, and therapy in hepatocellular carcinoma? Hepatology, 2013; 57: 840-47

9. Garzon R, Calin GA, Croce CM: MicroRNAs in cancer. Annu Rev Med, 2009; 60: $167-79$

10. Ambros V: The functions of animal microRNAs. Nature, 2004; 431: 350-55

11. Hou J, Lin L, Zhou W et al: Identification of miRNomes in human liver and hepatocellular carcinoma reveals miR-199a/b-3p as therapeutic target for hepatocellular carcinoma. Cancer Cell, 2011; 19: 232-43

12. Li D, Liu X, Lin L et al: MicroRNA-99a inhibits hepatocellular carcinoma growth and correlates with prognosis of patients with hepatocellular carcinoma. J Biol Chem, 2011; 286: 36677-85

13. Mendell JT, Olson EN: MicroRNAs in stress signaling and human disease. Cell, 2012; 148: 1172-87

14. Croce $C M$ : Causes and consequences of microRNA dysregulation in cancer Nat Rev Genet, 2009; 10: 704-14

15. Iorio MV, Visone R, Di Leva $\mathrm{G}$ et al: MicroRNA signatures in human ovarian cancer. Cancer Res, 2007; 67: 8699-707

16. Resnick KE, Alder H, Hagan JP et al: The detection of differentially expressed microRNAs from the serum of ovarian cancer patients using a novel realtime PCR platform. Gynecol Oncol, 2009; 112: 55-59

17. Chung YW, Bae HS, Song JY et al: Detection of microRNA as novel biomarkers of epithelial ovarian cancer from the serum of ovarian cancer patients. Int J Gynecol Cancer, 2013; 23: 673-79

18. Shapira I, Oswald M, Lovecchio J et al: Circulating biomarkers for detection of ovarian cancer and predicting cancer outcomes. Br J Cancer, 2014; 110: 976-83

19. Suryawanshi S, Vlad AM, Lin HM et al: Plasma microRNAs as novel biomarkers for endometriosis and endometriosis-associated ovarian cancer Clin Cancer Res, 2013; 19: 1213-24

20. Zheng $H$, Zhang L, Zhao $Y$ et al: Plasma miRNAs as diagnostic and prognostic biomarkers for ovarian cancer. PLoS One, 2013; 8: e77853

21. Kan CW, Hahn MA, Gard GB et al: Elevated levels of circulating microRNA-200 family members correlate with serous epithelial ovarian cancer. BMC Cancer, 2012; 12: 627

22. Romano F, Garancini M, Uggeri F et al: Surgical treatment of liver metastases of gastric cancer: state of the art. World J Surg Oncol, 2012; 10: 157

23. Lim L, Balakrishnan A, Huskey $\mathrm{N}$ et al: MicroRNA-494 within an oncogenic microRNA megacluster regulates G1/S transition in liver tumorigenesis through suppression of mutated in colorectal cancer. Hepatology, 2014; 59: 202-15

24. Olaru AV, Ghiaur G, Yamanaka S et al: MicroRNA down-regulated in human cholangiocarcinoma control cell cycle through multiple targets involved in the G1/S checkpoint. Hepatology, 2011; 54: 2089-98

\section{Conflict of interest}

The authors declare no conflicts interest.

25. Hong KJ, Wu DC, Cheng KH et al: RECK inhibits stemness gene expression and tumorigenicity of gastric cancer cells by suppressing ADAM-mediated Notch1 activation. J Cell Physiol, 2014; 229: 191-201

26. Yiwei T, Hua H, Hui G et al: HOTAIR interacting with MAPK1 regulates ovarian cancer skov3 cell proliferation, migration, and invasion. Med Sci Monit 2015; 21: 1856-63

27. Song B, Zhang C, Li G et al: MiR-940 inhibited pancreatic ductal adenocarcinoma growth by targeting MyD88. Cell Physiol Biochem, 2015; 35: 1167-77

28. Zhou Q, Yu Y: Upregulated CDK16 expression in serous epithelial ovarian cancer cells. Med Sci Monit, 2015; 21: 3409-14

29. Li H, Xu Y, Qiu W et al: Tissue miR-193b as a novel biomarker for patients with ovarian cancer. Med Sci Monit, 2015; 21: 3929-34

30. Liu C, Gao F, Li B et al: TLR4 knockout protects mice from radiation-induced thymic lymphoma by downregulation of IL6 and miR-21. Leukemia, 2011; 25: 1516-19

31. Liu C, Zhou C, Gao F et al: MiR-34a in age and tissue related radio-sensitivity and serum miR-34a as a novel indicator of radiation injury. Int J Biol Sci, 2011; 7: 221-33

32. Liu X, Ma L, Rao $Q$ et al: MiR-1271 inhibits ovarian cancer growth by targeting cyclin G1. Med Sci Monit, 2015; 21: 3152-58

33. Zhang L, Dong $\mathrm{Y}$, Zhu $\mathrm{N}$ et al: microRNA-139-5p exerts tumor suppressor function by targeting NOTCH1 in colorectal cancer. Mol Cancer, 2014; 13: 124

34. Cerami E, Gao J, Dogrusoz U et al: The cBio cancer genomics portal: an open platform for exploring multidimensional cancer genomics data. Cancer Discov, 2014; 2: 401-4

35. Gao J, Aksoy BA, Dogrusoz U et al: Integrative analysis of complex cancer genomics and clinical profiles using the cBioPortal. Sci Signal, 2013; 6(269): pl1

36. Lewis BP, Burge CB, Bartel DP: Conserved seed pairing, often flanked by adenosines, indicates that thousands of human genes are microRNA targets. Cell. 2005; 120: 15-20

37. Friedman RC, Farh KK, Burge CB, Bartel DP: Most mammalian mRNAs are conserved targets of microRNAs. Genome Res, 2009; 19: 92-105

38. Grimson A, Farh KK, Johnston WK et al: MicroRNA targeting specificity in mammals: determinants beyond seed pairing. Mol Cell, 2007; 27: 91-105

39. Garcia DM, Baek D, Shin C et al: Weak seed-pairing stability and high target-site abundance decrease the proficiency of Isy- 6 and other microRNAs. Nat Struct Mol Biol, 2011; 18: 1139-46

40. Lewis BP, Shih IH, Jones-Rhoades MW et al: Prediction of mammalian microRNA targets. Cell, 2003; 115(7): 787-98

41. Lee S, Paulson KG, Murchison EP et al: Identification and validation of a novel mature microRNA encoded by the Merkel cell polyomavirus in human Merkel cell carcinomas. J Clin Virol, 2011; 52: 272-75

42. Lin L, Liang $H$, Wang $Y$ et al: microRNA-141 inhibits cell proliferation and invasion and promotes apoptosis by targeting hepatocyte nuclear factor3beta in hepatocellular carcinoma cells, BMC Cancer, 2014; 14: 879

43. Wu N, Zhang C, Bai C et al: MiR-4782-3p inhibited non-small cell lung cancer growth via USP14. Cell Physiol Biochem, 2014; 33: 457-67

44. Grentzmann G, Ingram JA, Kelly PJ et al: A dual-luciferase reporter system for studying recoding signals. RNA, 1998; 4: 479-86

45. Cancer Genome Atlas Research Network, Weinstein JN, Collisson EA, Mills GB et al: The Cancer Genome Atlas Pan-Cancer analysis project, Nat Genet, 2013; 45: 1113-20

46. Little CD, Nau MM, Carney DN et al: Amplification and expression of the Cmyc oncogene in human lung cancer cell lines. Nature, 1983; 306: 194-96

47. Dang CV, O’Donnell KA, Zeller KI et al: The c-Myc target gene network. Semin Cancer Biol, 2006; 16: 253-64

48. Jackstadt $\mathrm{R}$, Hermeking $\mathrm{H}$ : MicroRNAs as regulators and mediators of $\mathrm{c}$ MYC function, Biochim Biophys Acta, 2015; 1849: 544-53 
49. Liu Y, Li X, Zhu S et al: Ectopic expression of miR-494 inhibited the proliferation, invasion and chemoresistance of pancreatic cancer by regulating SIRT1 and c-Myc. Gene Ther, 2015; 22: 729-38

50. Shen PF, Chen XQ, Liao YC et al: MicroRNA-494-3p targets CXCR4 to suppress the proliferation, invasion, and migration of prostate cancer. Prostate, 2014; 74: 756-67

51. Romano G, Acunzo M, Garofalo M et al: MiR-494 is regulated by ERK $1 / 2$ and modulates TRAIL-induced apoptosis in non-small-cell lung cancer through BIM down-regulation. Proc Natl Acad Sci USA, 2012; 109(41): 16570-75

52. Kim WK, Park M, Kim YK et al: MicroRNA-494 downregulates KIT and inhibits gastrointestinal stromal tumor cell proliferation, Clin Cancer Res, 2011; 17: 7584-94

53. Yamanaka S, Campbell NR, An F et al: Coordinated effects of microRNA-494 induce $\mathrm{G}(2) / \mathrm{M}$ arrest in human cholangiocarcinoma. Cell cycle, 2012; 11: 2729-38
54. Li N, Zhao X, Wang L et al: miR-494 suppresses tumor growth of epithelial ovarian carcinoma by targeting IGF1R. Tumour Biol, 2015 [Epub ahead of print]

55. Duan H, Jiang Y, Zhang H, Wu Y: MiR-320 and miR-494 affect cell cycles of primary murine bronchial epithelial cells exposed to benzo[a]pyrene. Toxicol In Vitro, 2010; 24(3): 928-35

56. Zhao JJ, Yang J, Lin J et al: Identification of miRNAs associated with tumorigenesis of retinoblastoma by miRNA microarray analysis. Childs Nerv Syst, 2009; 25(1): 13-20

57. Liu K, Liu S, Zhang W et al: miR-494 promotes cell proliferation, migration and invasion, and increased sorafenib resistance in hepatocellular carcinoma by targeting PTEN. Oncol Rep, 2015; 34: 1003-10. 